\title{
Is a matched unrelated donor search needed for all allogeneic transplant candidates?
}

\author{
Stefan O. Ciurea, ${ }^{1}$ Maria Cecilia Borges Bittencourt, ${ }^{1}$ Denái R. Milton, ${ }^{2}$ Kai Cao, ${ }^{3}$ Piyanuch Kongtim, ${ }^{1}$ Gabriela Rondon, ${ }^{1}$ Julianne Chen, ${ }^{1}$ \\ Marina Konopleva, ${ }^{4}$ Jorge M. Ramos Perez, ${ }^{1}$ Mohammed F. El Shazly, ${ }^{1}$ Majdi Aljadayeh, ${ }^{1}$ Michele Alvarez, ${ }^{1}$ Jin Im, ${ }^{1}$ Gheath Al-Atrash, ${ }^{1}$ \\ Rohtesh Mehta, ${ }^{1}$ Uday Popat, ${ }^{1}$ Qaiser Bashir, ${ }^{1}$ Betul Oran, ${ }^{1}$ Chitra M. Hosing, ${ }^{1}$ Issa F. Khouri, ${ }^{1}$ Partow Kebriaei, ${ }^{1}$ and Richard E. Champlin ${ }^{1}$ \\ ${ }^{1}$ Department of Stem Cell Transplantation and Cellular Therapy, ${ }^{2}$ Department of Biostatistics, ${ }^{3}$ Department of Pathology, and ${ }^{4}$ Department of Leukemia, The University of Texas \\ MD Anderson Cancer Center, Houston, TX
}

\section{Key Points}

- Race, haplotype frequency, and disease status at time of MUD search influence the probability of identifying a MUD/receiving a transplant.

- Patients with a low likelihood of receiving a MUD transplant may proceed to a haploidentical transplant as soon as indicated.
Donor availability for allogeneic transplantation remains an important factor in determining outcomes of a successful transplant. We examined outcomes of 242 patients treated over 3 years who had a matched unrelated donor (MUD) search at our institution. One hundred sixty patients (66\%) had a 10 of 10 MUD identified, and 85 (53\%) proceeded to MUD transplantation. White patients and those with common haplotypes were more likely to have a MUD identified (odds ratio [OR], $7.4[P<.0001]$; OR, $41.6[P<.0001]$ ), and were more likely to proceed to transplantation with a MUD (OR, $11.2[P<.0001]$; OR, 85.1 $[P=.002])$. In addition, patients who were newly diagnosed/in remission at the time of MUD search had a higher probability of receiving a transplant (OR, $2.01[P=.013]$ ) and better progression-free survival (PFS; $P<.0001$ ). In multivariate analysis for patients who received a transplant, donor type did not influence PFS at 3 years, which was 40\% for MUD and 57\% for haploidentical transplants, respectively (hazard ratio, $1.2[P=.50]$ ). In conclusion, race, haplotype frequency, and disease status at the time of MUD search influence the probability of identifying a MUD and receiving a transplant. Patients with a low likelihood of receiving a MUD transplant may proceed to a haploidentical transplant as soon as indicated, as this approach does not appear to compromise transplant outcomes.

\section{Introduction}

Allogeneic hematopoietic stem cell transplantation (HSCT) is a curative treatment and has become a standard of care for patients with high-risk or advanced hematologic malignancies. ${ }^{1}$ The use of HSCT has expanded rapidly over the past decades owing to substantial advances in transplant procedures and supportive care. ${ }^{2-4}$ However, providing a suitable donor for HSCT for all patients in an optimal period of time remains an unmet need. Even though a fully HLA-matched related donor (MRD) is considered the first graft choice for transplantation, approximately two-thirds of patients who need HSCT do not have a MRD available, thus most patients must rely on alternative donor choices. ${ }^{5}$ An HLA-matched unrelated donor (MUD) has been accepted as the next best option. The success of unrelated-donor HSCT is primarily influenced by the degree of HLA matching between the donor and the recipient. ${ }^{6-8}$ Highresolution matching at 8 alleles at HLA-A, -B, -C, and -DRB1 ( 8 of 8 match) is considered standard for unrelated donor transplantation, ${ }^{7,9}$ as transplant outcomes after MUD grafts approximate those of MRD grafts. $^{10-13}$ Hence, most transplant centers usually proceed with an unrelated donor search for all patients in need of a transplant if no MRD is available. However, identification of a MUD may be challenging due to donor availability for non-white populations or mixed-race individuals. In addition, the MUD search and procurement of stem cell product usually take much longer (on average 3-4 months) ${ }^{14}$ 
than that of a related donor ( $\sim 1$ month). As a result, many patients may develop progressive disease or become medically unfit while waiting for a MUD transplant, which might have a negative impact on overall survival. With recent improvements in haploidentical donor transplant outcomes resembling those of MUD transplants, ${ }^{15}$ it remains unclear whether it is better to proceed with a haploidentical donor transplant as soon as possible at least for certain groups of patients as opposed to waiting for a suitable MUD, before disease progression or development of an infection that might preclude proceeding to transplantation.

Therefore, in this study, we hypothesized that certain groups of patients may not benefit from performing a MUD search. We sought to evaluate availability of a MUD donor, ability to proceed to transplant with a MUD, as well as transplant outcomes for all patients who had a MUD search started at our institution.

\section{Methods}

All 242 consecutive patients with a diagnosis of primary/secondary acute myeloid leukemia (AML) and myelodysplastic syndrome (MDS) who had an unrelated donor search performed between January 2013 and December 2015 at the University of Texas MD Anderson Cancer Center (UTMDACC) and had follow-up at our institution were identified through review of the institutional database and were included in this analysis. All patients provided written informed consent for the treatment in accordance with the Declaration of Helsinki. The UTMDACC Institutional Review Board approved the treatment protocols and this retrospective study.

\section{HLA typing and unrelated donor search}

All patients had intermediate-/high-resolution HLA typing performed by DNA sequencing. Unrelated donor searches were done through Bone Marrow Donor Worldwide (BMDW) and/or the National Marrow Donor Program (NMDP). A full MUD was defined as a 10 of 10 allele match at HLA-A, -B, -C, -DRB1, and -DQB1 between the donor and the recipient whereas a single-allele/-antigen mismatch at any of these loci was designated as a 9 of 10 HLA match. A common haplotype was defined as $1 / 2000$ in frequency or greater based on the NMDP Registry Haplotype Frequencies. ${ }^{16}$ Length of search was defined as the interval from the start of the search to time of identifying an acceptable 10 of 10 MUD. According to standard operating procedures, our first donor choice for transplantation is a MRD. HLA typing of the family members was sent concomitantly or as soon as possible after patient's typing. For patients with a diagnosis of acute leukemia, the standard procedure is to begin a MUD search as soon as the results of the HLA typing of the recipient is obtained, often pending MRD identification. If no 10 of 10 MUD was available, the choice between a 9 of 10 MUD, haploidentical or umbilical cord blood (UCB), was based on the treating physician's decision.

\section{Statistical methods}

The associations between MUD identification and types of transplantation and subgroups of interest, including race, haplotype frequency, and remission status at the time of MUD search, were assessed using either the Fisher's exact test or its generalization. In addition, logistic regression modeling was performed to evaluate the likelihood of successful 10 of 10 MUD identification, receiving a MUD transplant, and receiving any transplant types in these subgroups of interest. Progression-free survival (PFS) was computed from date of
MUD search or from date of stem cell infusion (for type of transplant) to date of disease progression, death (if died without disease progression), or last follow-up. Patients who were alive and did not experience progression of disease at the last follow-up date were censored. The Kaplan-Meier method was used to estimate PFS, and differences in PFS between groups were assessed using the log-rank test. Moreover, associations between PFS and measures of interest were examined using Cox proportional hazards regression models. Assessment of transplant (yes vs no) from date of MUD search was included in the regression models as a time-dependent covariate. All statistical analyses were performed using SAS 9.3 for Windows (SAS Institute Inc, Cary, NC). All statistical tests used a significance level of $5 \%$. No adjustments for multiple testing were made.

\section{Results}

\section{Patient characteristics}

The analysis included 242 patients with primary AML ( $n=206$; $85 \%)$, secondary AML from an antecedent MDS (MDS/AML) ( $n=23 ; 10 \%$ ) or from myeloproliferative neoplasm (MPN/AML) ( $n=10 ; 4 \%$ ), and MDS ( $n=3 ; 1 \%)$, who had a MUD search preformed at UTMDACC over a 3-year period (1 January 2013 through 21 December 2015). Patient characteristics are summarized in Table 1. The median age was 58 years (range, 9-80 years); 123 patients (51\%) were male and 182 patients (75\%) were white. One hundred thirteen patients $(47 \%)$ had disease in complete remission at the time of MUD search, whereas $35(14 \%)$ had primary induction failure (PIF), $43(18 \%)$ had relapse/refractory disease, and 49 (20\%) were newly diagnosed. The median time from diagnosis to MUD search was 79 days (range, $0-5$ days; 981 days). Patients were grouped into 2 categories based on disease status at MUD search: (1) newly diagnosed and in complete remission at the time of MUD search and (2) patients with PIF and relapsed-refractory disease. One hundred ninety patients (79\%) had common haplotypes; the rest had uncommon haplotypes according to NMDP Registry Haplotype Frequencies. ${ }^{16}$

\section{Characteristics associated with successful 10 of 10 MUD identification}

One hundred sixty patients (66\%) had a 10 of 10 MUD identified with the median time from starting a MUD search to a MUD identification of 20 days (range, 6-746 days).

The majority of white patients (85\%) had common haplotypes compared with only $58 \%$ of patients of other races $(P<.0001)$ (Table 2). Both race and haplotype frequencies were significantly associated with 10 of 10 MUD identification. A 10 of 10 MUD was found in 141 of 182 white patients (77\%), whereas only 19 of 60 non-white patients (32\%) had a 10 of 10 MUD identified $(P<$ .0001) (Table 2). A significantly higher percentage of patients with common haplotypes had 10 of 10 MUD identification compared with those of uncommon haplotypes ( $82 \%$ vs $10 \% ; P<.0001)$ (Table 2). Taken together, race and haplotype frequency were independently associated with 10 of 10 MUD identification, where the odds for identification were 6.8 times (95\% confidence interval $[\mathrm{Cl}$, 3.1-14.9) higher for white patients compared with non-white patients $(P<.0001)$ and 39 times $(95 \% \mathrm{Cl}, 13.9-110.4)$ greater for patients with common haplotypes compared with uncommon haplotypes $(P<.0001)$ (Table 3$)$. 


\section{Table 1. Patients' characteristics}

\begin{tabular}{|c|c|}
\hline Measure & All patients, $N=242$ \\
\hline \multicolumn{2}{|l|}{ Sex, n (\%) } \\
\hline Male & $123(51)$ \\
\hline Female & $119(49)$ \\
\hline Median age (range), y & $57.8(9.3-79.6)$ \\
\hline \multicolumn{2}{|l|}{ White, n (\%) } \\
\hline Yes & $182(75)$ \\
\hline No & $60(25)$ \\
\hline \multicolumn{2}{|l|}{ Diagnosis, n (\%) } \\
\hline AML & $206(85)$ \\
\hline MDS/AML & $23(10)$ \\
\hline MPD/AML & $10(4)$ \\
\hline MDS & $3(1)$ \\
\hline \multicolumn{2}{|c|}{ Disease status at MUD search, $n(\%)$} \\
\hline Remission & $113(47)$ \\
\hline Not in remission & $128(53)$ \\
\hline Missing & $1(0.4)$ \\
\hline \multicolumn{2}{|c|}{ Reason not in remission, $\mathbf{n}(\%)$} \\
\hline PIF & $35(28)$ \\
\hline Relapsed/refractory & $43(34)$ \\
\hline Newly diagnosed & $50(39)$ \\
\hline \multicolumn{2}{|c|}{ Haplotype frequency, n (\%) } \\
\hline Common & $190(79)$ \\
\hline Uncommon & $52(21)$ \\
\hline \multicolumn{2}{|c|}{ 10/10 MUD identified, $n$ (\%) } \\
\hline Yes & $160(66)$ \\
\hline No & $82(34)$ \\
\hline \multicolumn{2}{|l|}{ Transplant type, n (\%) } \\
\hline MUD & $85(35)$ \\
\hline Other & $66(27)$ \\
\hline None & $91(38)$ \\
\hline \multicolumn{2}{|c|}{ Reason for not receiving a transplant, $\mathbf{n}(\%)$} \\
\hline Disease progression & $36(15)$ \\
\hline Refractory & $19(8)$ \\
\hline Other & $36(15)$ \\
\hline \multicolumn{2}{|c|}{$\begin{array}{l}\text { Median time to SCT from MUD search date } \\
\text { (range), mo }\end{array}$} \\
\hline 10/10 MUD $(n=85)$ & $2.9(1.4-13.0)$ \\
\hline MRD $(n=15)$ & $2.3(1.6-6.4)$ \\
\hline $9 / 10$ MUD $(n=9)$ & $4.6(3.7-13.1)$ \\
\hline Haploidentical $(n=20)$ & $3.5(0.9-13.4)$ \\
\hline $\mathrm{UCB}(\mathrm{n}=22)$ & $3.2(1.7-14.7)$ \\
\hline
\end{tabular}

MPD, myeloproliferative disorder; SCT, stem cell transplant.

\section{Characteristics associated with proceeding to a 10 of 10 MUD transplant}

Despite a successful MUD search, only 85 of 160 patients (53\%) proceeded to MUD transplantation, whereas 66 patients (27\%) received transplants from other donor types (9 [4\%] 9 of 10 MUD,
20 haploidentical [8\%], 22 cord blood [9\%], and 15 matched sibling donor transplant [6\%]), and 91 patients (38\%) did not receive a transplant. The reasons for not proceeding to transplant included disease progression $(n=36 ; 40 \%)$, refractory disease $(n=19 ; 21 \%)$, and other causes $(n=36 ; 40 \%)$. Among other causes were doctor's preference (8 of $34 ; 24 \%$ ), patient's preference $(7$ of $34 ; 21 \%$ ), poor performance status ( 3 of 34 ; $9 \%$ ), insurance denial (3 of $34 ; 9 \%)$, and unknown causes (13 of $34 ; 38 \%)$.

The median time from MUD search to 10 of 10 MUD transplant was 2.9 months (range, 1.4-13.0 months), to MRD transplant was 2.3 months (range, 1.6-6.4 months), to a haploidentical transplant was 3.5 months (range, 0.9-13.4 months), to a 9 of 10 MUD transplant was 4.6 months (range, 3.7-13.1 months), and to a UCB transplant was 3.2 months (range, 1.7-14.7 months) (Kruskal-Wallis $P=.002$ ).

Similar with MUD identification, both race and haplotype frequencies were significantly associated with receiving a 10 of 10 MUD transplant (supplemental Figure 1). Eighty-one white patients (45\%) and 4 non-white patients (7\%) proceeded to a 10 of 10 MUD transplant $(P<.0001)$. Eighty-five of 190 patients $(45 \%)$ with common haplotypes received a MUD transplant, whereas none of the patients who had uncommon haplotype received a MUD transplant $(P<.0001)$ (Table 2). When race and haplotype frequency were considered together, both factors were independently associated with proceeding to MUD transplantation (white vs non-white: odds ratio [OR], $7.7 ; 95 \% \mathrm{Cl}, 2.7-21.7 ; P=.0001$ ) (common haplotype vs uncommon haplotype: OR, 66; $95 \% \mathrm{Cl}$, 3.9 to $>999 ; P=.004$ ) (Table 3). In contrast, when transplant from all donor types were considered (ie, any transplant vs no transplant), neither race nor haplotype frequency was associated with proceeding to transplantation. Instead, it was patients with early disease (either in remission or newly diagnosed) who were more likely to proceed to transplantation compared with those with more advanced disease (PIF or relapse/refractory disease) (OR, 2.0; $95 \% \mathrm{Cl}, 1.1-3.4 ; P=.02$ ) (Table 3).

\section{PFS for patients with a MUD search}

The median follow-up duration for survivors $(n=112)$ was 17.7 months (range, 1.4-48.1 months). The 3-year PFS for all 242 patients who had MUD search was 31\%. Higher 3-year PFS was seen in patients who received transplantation compared with no transplantation (39\% vs $19 \%$ at 3 years). In addition, patients who received transplantation experienced decreased risk of progression or death compared with those who did not receive a transplant (hazard ratio $[\mathrm{HR}], 0.34 ; 95 \% \mathrm{Cl}, 0.25-0.48$; $P<.001$ ). The 3-year PFS for patients receiving MRD, haploidentical, 10 of 10 MUD, 9 of 10 MUD, and cord blood were $65 \%, 57 \%, 40 \%, 42 \%$, and 20\%, respectively (Figure 1). For patients with early disease (in remission/newly diagnosed) compared with those with more advanced disease (PIF/active disease), the 3-year PFS rates were $48 \%$ and $13 \%$, respectively $(P<.001)$ (Figure 2).

A multivariable analysis (MVA) for PFS of patients who received a transplant (starting from date of transplant; $N=151$ ) considering disease type, disease status, cytogenetic risk, donor type, and time from a MUD search to transplant showed significant impact on transplant outcomes for disease status, cytogenetics, and time from 


\begin{tabular}{|c|c|c|c|c|c|}
\hline \multirow[b]{2}{*}{ Measure } & \multicolumn{2}{|c|}{ Race } & \multicolumn{2}{|c|}{ Haplotype frequency } & \multirow[b]{2}{*}{$\boldsymbol{P}^{*}$} \\
\hline & White, $\mathbf{N}=182$ & Other, $\mathbf{N}=60$ & Common, $\mathbf{N}=190$ & Uncommon, $\mathbf{N}=52$ & \\
\hline \multicolumn{6}{|c|}{ Haplotype frequency, $n(\%)$} \\
\hline Common & $155(85)$ & $35(58)$ & & & $<.0001$ \\
\hline Uncommon & $27(15)$ & $25(42)$ & & & \\
\hline \multicolumn{6}{|c|}{ 10/10 MUD identified, n (\%) } \\
\hline Yes $(N=160)$ & $141(77)$ & $19(32)$ & & & $<.0001$ \\
\hline No $(\mathrm{N}=82)$ & $41(23)$ & $41(68)$ & & & \\
\hline \multicolumn{6}{|c|}{ Transplant type, n (\%) } \\
\hline 10/10 MUD & $81(45)$ & $4(7)$ & & & $<.0001 \dagger$ \\
\hline Other & $39(21)$ & $27(45)$ & & & \\
\hline None & $62(34)$ & $29(48)$ & & & \\
\hline \multicolumn{6}{|c|}{ 10/10 MUD identified, $n$ (\%) } \\
\hline Yes & & & $155(82)$ & $5(10)$ & $<.0001$ \\
\hline No & & & $35(18)$ & $47(90)$ & \\
\hline \multicolumn{6}{|c|}{ Transplant type, n (\%) } \\
\hline 10/10 MUD & & & $85(45)$ & 0 & $<.0001+$ \\
\hline Other & & & $39(21)$ & $27(52)$ & \\
\hline None & & & $66(35)$ & $25(48)$ & \\
\hline
\end{tabular}

*Fisher's exact test.

tGeneralized Fisher's exact test.

a MUD search to transplant, whereas donor type did not impact transplant PFS (Table 4).

A second MVA for PFS was performed for all patients who had a MUD search $(\mathrm{N}=242)$ considering haplotype (common vs uncommon), race (white vs non-white), cytogenetics (adverse vs intermediate/favorable), diagnosis (de novo AML vs other), disease status at MUD search (newly diagnosed/complete remission vs PIF/ relapsed/refractory), and receiving a transplant (yes vs no). Patients who had intermediate/favorable cytogenetics, were diagnosed with de novo AML, were newly diagnosed/complete remission, and had received a transplant experienced significantly better PFS compared with their counterparts (Table 4).

\section{Race, haplotype, and disease status combination}

The percentages of patients who had a MUD identified and had received a MUD transplant, as well as the 3-year PFS for patients based on race, haplotype, and disease status at the time of MUD search, are presented in Table 5. The highest percentages were observed for white patients who were newly diagnosed/complete remission with common haplotype (60\% MUD identified, 69\% MUD transplant, 3-year PFS rate of 46\%), whereas the patient group with the lowest percentages was non-white patients with PIF/relapsed/ refractory and had uncommon haplotype (1\% MUD identified, 0\% MUD transplant, 3-year PFS rate of 0\%) (Table 5).

\section{Discussion}

A continuous increase in unrelated donor availability worldwide, now to over 27 million volunteer donors, ${ }^{17}$ has increased access to transplantation especially for the white population. According to a report on HSCT activity worldwide in 2012, compared with 2006 , an increase of $\sim 50 \%$ of allogeneic stem cell transplant activity was observed with a major increment seen in unrelated donor compared with related donor transplants. ${ }^{18}$ However, a big gap between need and availability of unrelated donors remains,

Table 3. Association between race, haplotype frequency, and disease status and MUD identified, MUD transplant received, and any transplant received: multivariable models

\begin{tabular}{|c|c|c|c|}
\hline Outcome & Predictor & Odds ratio $(95 \% \mathrm{Cl})$ & $\boldsymbol{P}$ \\
\hline \multirow[t]{2}{*}{ 10/10 MUD identified } & White vs other & $6.8(3.1-14.9)$ & $<.0001$ \\
\hline & Common haplotype vs uncommon haplotype & $39.2(13.9-110.4)$ & $<.0001$ \\
\hline \multirow[t]{2}{*}{ 10/10 MUD transplant } & White vs other & $7.7(2.7-21.7)$ & .0001 \\
\hline & Common haplotype vs uncommon haplotype & $66.3(3.9->999)$ & .004 \\
\hline \multirow[t]{3}{*}{ All transplant types } & White vs other & $1.5(0.8-2.9)$ & 18 \\
\hline & Common haplotype vs uncommon haplotype & $1.5(0.8-2.8)$ & 27 \\
\hline & Remission/newly diagnosed vs PIF/relapsed/refractory & $2.0(1.1-3.4)$ & .02 \\
\hline
\end{tabular}




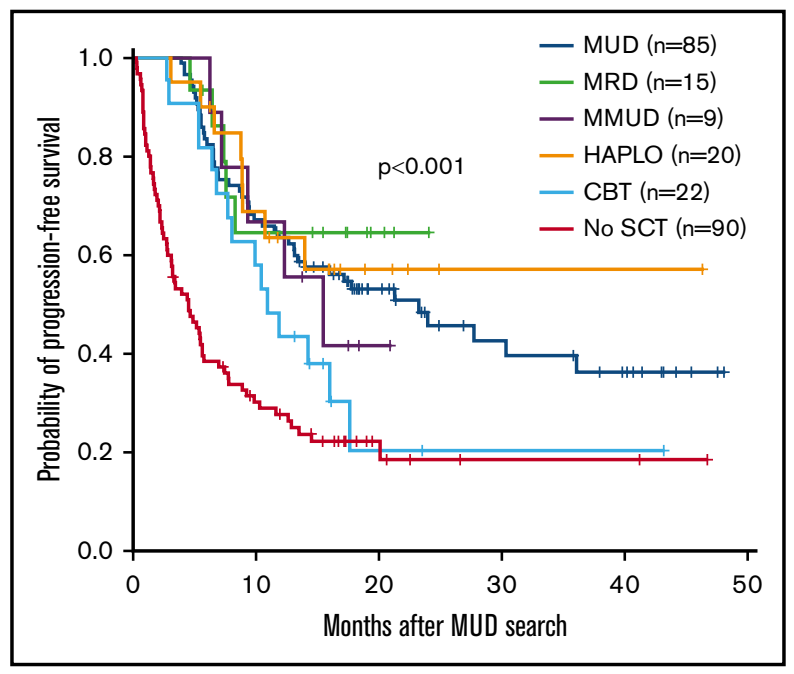

Figure 1. PFS according to type of transplant. CBT, cord blood transplant; HAPLO, haploidentical donor; MMUD, mismatched unrelated donor; SCT, stem cell transplant.

especially for the non-white population. The likelihood that a patient will find an optimal unrelated donor varies greatly based on genetic variability within a population or degree of an HLA match required. According to NMDP data, white patients represent $\sim 50 \%$ of all volunteer unrelated donors, whereas the composition of other ethnic groups such as African American, Hispanic, or Asian is only $\sim 20 \%$. $^{19}$ Besides a poor representation in donor registries, many racial groups have a high degree of genetic diversity within population (highest in African Americans), which makes it more challenging for these patients to find a suitable unrelated donor. Challenges in finding an optimal MUD in certain populations, and also time and expense spent on a MUD search, can be major barriers to effectively reaching transplantation. Results from a cost-analysis study by van Agthoven et al showed that the cost of MUD transplant per patient was much higher than the average cost of allogeneic transplant and nearly onethird of these costs were spent on the search for a suitable donor. ${ }^{20}$

Haploidentical transplants compensate for the lack of unrelated donors in the non-white population. During the last decade, several novel approaches have been developed to control the intense bidirectional alloreactivity between the donor and the recipient. One of the most successful methods is using posttransplant high-dose cyclophosphamide (PTCY) to selectively deplete alloreactive T cells following T-cell-replete haploidentical transplantation. Using this approach, the treatment-related mortality has been decreased with multiple retrospective studies now showing similar outcomes between haploidentical transplantation and HLA-matched transplants, including MUD transplants. ${ }^{15,21-28}$ With improvements in haploidentical transplant outcomes and wide availability of haploidentical donors, major questions arise like whether one should proceed to transplantation before a MUD is identified if there is a low likelihood of identifying an unrelated donor, and whether one should wait to determine whether a MUD is available if the transplant is urgently needed.

Previous studies have shown that the probability of finding an unrelated donor for transplantation varies significantly based on the race of the recipient. According to a study by Gragert et al using population-based genetic models to predict the likelihood of

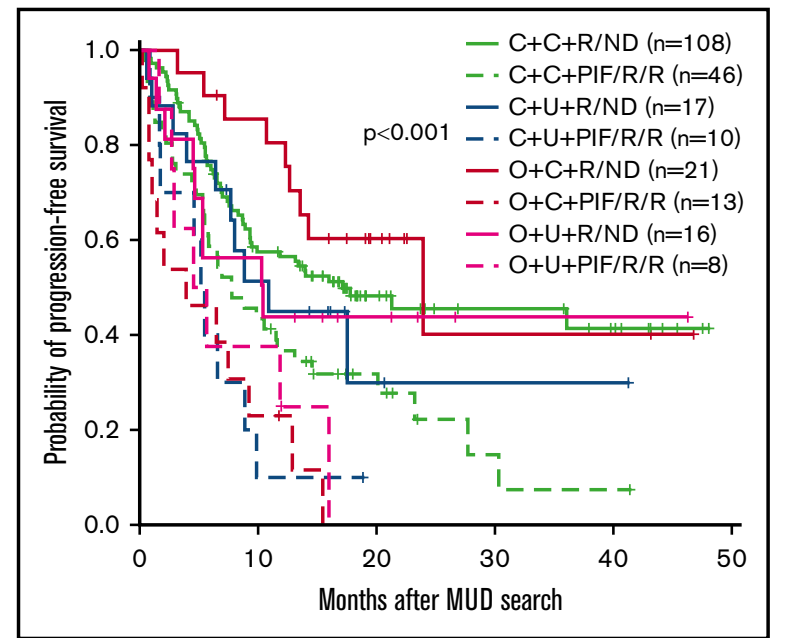

Figure 2. PFS according to race/haplotype frequency/disease status at the time of MUD search. $\mathrm{C}+\mathrm{C}+\mathrm{R} / \mathrm{ND}=$ white, common haplotype, and remission/newly diagnosed; $\mathrm{C}+\mathrm{C}+\mathrm{PIF} / \mathrm{R} / \mathrm{R}=$ white, common haplotype, and PIF/relapsed/refractory; $\mathrm{C}+\mathrm{U}+\mathrm{R} / \mathrm{ND}=$ white, uncommon haplotype, remission/newly diagnosed; $\mathrm{C}+\mathrm{U}+\mathrm{PIF} / \mathrm{R} / \mathrm{R}=$ white, uncommon haplotype, and $\mathrm{PIF} / \mathrm{relapsed} /$ refractory; $\mathrm{O}+\mathrm{C}+\mathrm{R} / \mathrm{ND}=$ other race, common haplotype, and remission/newly diagnosed; $\mathrm{O}+\mathrm{C}+\mathrm{PIF} / \mathrm{R} / \mathrm{R}=$ other race, common haplotype, and PIF/relapsed/refractory; $\mathrm{O}+\mathrm{U}+\mathrm{R} / \mathrm{ND}=$ other race, uncommon haplotype, remission/newly diagnosed; $\mathrm{O}+\mathrm{U}+\mathrm{PIF} / \mathrm{R} / \mathrm{R}=$ other race, uncommon haplotype, and PIF/relapsed/refractory.

identifying a suitable donor from the NMDP donor registry, the likelihood of finding an available 8 of 8 MUD was 75\% for white patients of European descent, only $46 \%$ for white patients of Middle Eastern or North African descent, and $<20 \%$ for Africans or African Americans. ${ }^{29}$ With an HLA-mismatched donor (7 of 8 MUD), most ethnic groups appeared to have a donor for transplantation; however, we were not able to confirm that in a retrospective analysis of race in individuals who had a transplant at our institution over a 25-year period, when we found that the actual likelihood of having a mismatched MUD was about the same both in the white and nonwhite population as the probability of finding a MUD. ${ }^{30}$

Pidala et al previously noted at a single institution that an HLA 8 of 8 MUD was available for $54 \%$ of all patients who received transplants, with white patients more likely to find a MUD (79\%), and white patients, in addition to patients with younger age, lower Center for International Blood and Marrow Transplant Research (CIBMTR) risk, and 8 of $8 \mathrm{HLA}$ matching, more likely to reach transplantation. ${ }^{31}$ In our analysis, we found that patients with an uncommon haplotype were very unlikely to have a MUD identified and proceed to a MUD transplant. In addition, those with more advanced disease at the time of MUD search were less likely to receive transplants compared with those with early disease (newly diagnosed) or in remission at the time of MUD search. As previously noted, the percentage of 10 of 10 MUD identification for white patients was $\sim 80 \%$, whereas the majority of non-white patients could not identify an optimal MUD, and only $7 \%$ of non-white patients could finally proceed to MUD transplant. Furthermore, we also found a significant association between racial group and haplotype frequency; both factors strongly influenced not only the likelihood of finding an optimal MUD but also the likelihood of undergoing MUD transplantation. 
Table 4. Multivariable analysis for PFS for patients receiving a transplant and for all patients who had a MUD search

\begin{tabular}{|c|c|c|}
\hline Measure & HR $(95 \% \mathrm{Cl})$ & $\boldsymbol{P}$ \\
\hline \multicolumn{3}{|l|}{$\begin{array}{l}\text { Multivariable analysis for } \mathrm{PFS} \text { for patients } \\
\text { receiving a transplant, } \mathrm{N}=151\end{array}$} \\
\hline \multicolumn{3}{|l|}{ Donor } \\
\hline $\begin{array}{l}\text { Related (MRD/Haplotype) vs 10/10 MUD } \\
\text { and 9/10 MUD }\end{array}$ & $1.20(0.62-2.33)$ & .50 \\
\hline \multicolumn{3}{|l|}{ Disease status at transplant } \\
\hline CR1/2 vs other & $0.63(0.37-1.08)$ & .09 \\
\hline \multicolumn{3}{|l|}{ Cytogenetics } \\
\hline Adverse vs intermediate/favorable & $3.18(1.87-5.43)$ & $<.0001$ \\
\hline \multicolumn{3}{|l|}{ Diagnosis } \\
\hline De novo AML vs other & $0.39(0.19-0.79)$ & .009 \\
\hline Time from MUD search to transplant, continuous & $1.00(1.00-1.01)$ & .010 \\
\hline \multicolumn{3}{|l|}{$\begin{array}{l}\text { Multivariable analysis for PFS for all patients } \\
\text { who had a MUD search, } N=242\end{array}$} \\
\hline \multicolumn{3}{|l|}{ Race } \\
\hline White vs other & $0.98(0.66-1.46)$ & .92 \\
\hline \multicolumn{3}{|l|}{ Disease status at MUD search } \\
\hline Remission/newly diagnosed vs other & $0.52(0.36-0.74)$ & $<.001$ \\
\hline \multicolumn{3}{|l|}{ Cytogenetics } \\
\hline Adverse vs intermediate/favorable & $2.67(1.87-3.83)$ & $<.0001$ \\
\hline \multicolumn{3}{|l|}{ Diagnosis } \\
\hline De novo AML vs other & $0.40(0.26-0.63)$ & $<.0001$ \\
\hline \multicolumn{3}{|l|}{ Haplotype frequency } \\
\hline Common vs uncommon & $0.68(0.45-1.02)$ & .06 \\
\hline \multicolumn{3}{|l|}{ Transplant } \\
\hline Yes vs no & $0.32(0.23-0.45)$ & $<.0001$ \\
\hline
\end{tabular}

Interestingly, only $10 \%$ of patients with uncommon haplotypes had a 10 of 10 MUD identified and none of these patients could successfully proceed to MUD transplant.

According to our results, the median time from starting a MUD search to transplant was $\sim 3$ months, whereas doing a transplant with a haploidentical donor took on average 3.5 months, reflecting the current approach used in many centers, in which if a MUD is not available, patients might proceed to a haploidentical donor transplant. During this waiting period, many patients, especially those with more advanced disease, might experience disease relapse or become medically unfit for transplant, which might affect their survival. In the previous report, disease progression was the most common cause of not proceeding to transplantation in 35\% of the patients. ${ }^{31}$ Although we acknowledge that not all causes for not proceeding to transplant are donor related, we also found that relapse was the cause for not proceeding to transplant in $40 \%$ of patients and $15 \%$ of all patients who had a MUD search developed relapsed disease before being able to proceed to transplantation, especially those with more advanced disease at the time of MUD search. Consequently, this approach does not appear to be optimal, at least for a subgroup of patients with uncommon haplotypes or those with advanced disease: the first group is very unlikely to have a MUD donor identified and proceed to a MUD transplant, and, in the second group, the advanced nature of disease makes it unlikely to get to transplant before disease progression or other complications occur. Moreover, we have shown that proceeding to a haploidentical donor transplant does not compromise survival of these patients. Collectively, this evidence clearly demonstrates that at least some patients who have a lower likelihood of finding a MUD, and those who need to proceed to transplant urgently, may be candidates for an earlier alternative donor evaluation, especially a haploidentical related donor transplant, which can be performed much faster compared with completing a MUD search, to prevent (1) loss in time, (2) increased resources, (3) disease progression, or (4) becoming medically unfit to receive a transplant, potentially missing the opportunity to benefit from this lifesaving procedure. Future prospective studies are needed to determine whether proceeding directly to transplant with other donor types could improve outcomes in these patients.

In conclusion, our results suggest that not all patients considered for allogeneic stem cell transplantation require or benefit from a MUD search. Doing a MUD search may delay transplantation for patients who are very unlikely to have a MUD or have advanced disease and may progress before a MUD is identified. Hence, we propose using race, haplotype frequency, and disease status to appreciate the need for MUD search. Proceeding with a haploidentical donor may be advisable when the likelihood of finding a MUD is low or when the transplant is urgently needed, as our results suggest that proceeding with a haploidentical donor transplant does not compromise the outcomes of transplantation.

Table 5. Probability of identifying a MUD, proceeding to a MUD transplant, and PFS for all patients based on race, haplotype, and disease status at MUD search

\begin{tabular}{|c|c|c|c|c|}
\hline Race/haplotype/disease status at MUD search & $\begin{array}{c}\text { All patients, } \\
\mathrm{N}=\mathbf{2 4 0}, \mathrm{n}(\%)\end{array}$ & $\begin{array}{l}\text { 10/10 MUD identified, } \\
\mathrm{N}=159, \mathrm{n}(\%)\end{array}$ & $\begin{array}{l}\text { 10/10 MUD SCT, } \\
\mathrm{N}=\mathbf{8 4}, \mathrm{n}(\%)\end{array}$ & 3-y PFS, \% \\
\hline White + common haplotype + newly diagnosed/remission & $108(45)$ & $95(60)$ & $58(69)$ & 46 \\
\hline White + common haplotype + PIF/relapsed/refractory & $46(19)$ & $44(28)$ & $22(26)$ & 7 \\
\hline White + uncommon haplotype + newly diagnosed/remission & $17(7)$ & 0 & 0 & 30 \\
\hline White + uncommon haplotype + PIF/relapsed/refractory & $10(4)$ & $1(1)$ & 0 & 10 \\
\hline Non-white + common haplotype + newly diagnosed/remission & $21(9)$ & $9(6)$ & $3(4)$ & 40 \\
\hline Non-white + common haplotype + PIF/relapsed/refractory & $14(6)$ & $6(4)$ & $1(1)$ & 0 \\
\hline Non-white + uncommon haplotype + newly diagnosed/remission & $16(7)$ & $3(2)$ & 0 & 44 \\
\hline Non-white + uncommon haplotype + PIF/relapsed/refractory & $8(3)$ & $1(1)$ & 0 & 0 \\
\hline
\end{tabular}




\section{Acknowledgment}

This work was supported in part by the National Institutes of Health, National Cancer Institute Cancer Center Support grant P30 CA016672.

\section{Authorship}

Contribution: S.O.C. designed the study, collected some data, interpreted the results, and wrote the paper; M.C.B.B. and P. Kongtim contributed to manuscript writing; D.R.M. performed the statistical analysis, interpreted the results, and contributed to manuscript writing; K.C. performed the HLA typing and advised on the patients' haplotypes; G.R., J.C., and M. Alvarez contributed with data collection; M.K., U.P., Q.B., J.I., G.A.-A., R.M., B.O., C.M.H., I.F.K., and P. Kebriaei contributed with patient care; J.M.R.P., M.F.E.S., and $\mathrm{M}$. Aljadayeh contributed with interpretation of results and manuscript writing; R.E.C contributed with study design, treatment of the patients, and interpretation of results; and all authors reviewed and approved the manuscript.

Conflict-of-interest disclosure: The authors declare no competing financial interests.

Correspondence: Stefan O. Ciurea, Department of Stem Cell Transplantation and Cellular Therapy, The University of Texas MD Anderson Cancer Center, 1515 Holcombe Blvd, Unit 0423, Houston, TX 77030-4009; e-mail: sciurea@mdanderson.org.

\section{References}

1. Copelan EA. Hematopoietic stem-cell transplantation. N Engl J Med. 2006;354(17):1813-1826.

2. Gratwohl A, Pasquini MC, Aljurf M, et al; Worldwide Network for Blood and Marrow Transplantation (WBMT). One million haemopoietic stem-cell transplants: a retrospective observational study. Lancet Haematol. 2015;2(3):e91-e100.

3. Passweg JR, Baldomero H, Bader $\mathrm{P}$, et al. Use of haploidentical stem cell transplantation continues to increase: the 2015 European Society for Blood and Marrow Transplant activity survey report. Bone Marrow Transplant. 2017;52(6):811-817.

4. Passweg JR, Baldomero $\mathrm{H}$, Bader $\mathrm{P}$, et al. Hematopoietic stem cell transplantation in Europe 2014: more than 40000 transplants annually. Bone Marrow Transplant. 2016;51(6):786-792.

5. Ballen KK, King RJ, Chitphakdithai P, et al. The National Marrow Donor Program 20 years of unrelated donor hematopoietic cell transplantation. Biol Blood Marrow Transplant. 2008;14(suppl 9):2-7.

6. Flomenberg N, Baxter-Lowe LA, Confer D, et al. Impact of HLA class I and class II high-resolution matching on outcomes of unrelated donor bone marrow transplantation: HLA-C mismatching is associated with a strong adverse effect on transplantation outcome. Blood. 2004;104(7):1923-1930.

7. Lee SJ, Klein J, Haagenson M, et al. High-resolution donor-recipient HLA matching contributes to the success of unrelated donor marrow transplantation. Blood. 2007;110(13):4576-4583.

8. Horan J, Wang T, Haagenson M, et al. Evaluation of HLA matching in unrelated hematopoietic stem cell transplantation for nonmalignant disorders. Blood. 2012;120(14):2918-2924.

9. Bray RA, Hurley CK, Kamani NR, et al. National marrow donor program HLA matching guidelines for unrelated adult donor hematopoietic cell transplants. Biol Blood Marrow Transplant. 2008;14(suppl 9):45-53.

10. Segal E, Martens $\mathrm{M}, \mathrm{Wang} \mathrm{HL}$, et al. Comparing outcomes of matched related donor and matched unrelated donor hematopoietic cell transplants in adults with B-cell acute lymphoblastic leukemia. Cancer. 2017;123(17):3346-3355.

11. Saber W, Opie S, Rizzo JD, Zhang MJ, Horowitz MM, Schriber J. Outcomes after matched unrelated donor versus identical sibling hematopoietic cell transplantation in adults with acute myelogenous leukemia. Blood. 2012;119(17):3908-3916.

12. Appelbaum FR. Allogeneic hematopoietic cell transplantation for acute myeloid leukemia when a matched related donor is not available. Hematology Am Soc Hematol Educ Program. 2008;2008:412-417.

13. Brissot $\mathrm{E}$, Labopin $\mathrm{M}$, Stelljes $\mathrm{M}$, et al. Comparison of matched sibling donors versus unrelated donors in allogeneic stem cell transplantation for primary refractory acute myeloid leukemia: a study on behalf of the Acute Leukemia Working Party of the EBMT. J Hematol Oncol. 2017;10(1):130.

14. Krupski MC, Perentesis EMR, Sper C, Bonavita A, Fohl D, Davies SM. How long does it take to find a matched unrelated donor in 2016? Biol Blood Marrow Transplant. 2017;23(suppl 3):S238-S239.

15. Ciurea SO, Zhang MJ, Bacigalupo AA, et al. Haploidentical transplant with posttransplant cyclophosphamide vs matched unrelated donor transplant for acute myeloid leukemia. Blood. 2015;126(8):1033-1040.

16. WMDA. Number of donors per registry in WMDA. Available at: https://statistics.wmda.info/. Accessed 31 January 2018.

17. National Marrow Donor Program, a C.W. Bill Young Cell Transplantation Program (CWBYCTP) contractor. Donor Registry Data 2017. Rockville, MD: US Department of Health and Human Services, Health Resources and Services Administration, Healthcare Systems Bureau; 2017. Available from: https://bloodcell.transplant.hrsa.gov/research/registry_donor_data/index.html. Accessed 25 January 2018.

18. Niederwieser D, Baldomero H, Szer J, et al. Hematopoietic stem cell transplantation activity worldwide in 2012 and a SWOT analysis of the Worldwide Network for Blood and Marrow Transplantation Group including the global survey. Bone Marrow Transplant. 2016;51(6):778-785.

19. National Marrow Donor Program, a C. W. Bill Young Cell Transplantation Program (CWBYCTP) contractor. Donor Registry Data 2018. Rockville, MD: US Department of Health and Human Services, Health Resources and Services Administration, Healthcare Systems Bureau; 2018.

20. van Agthoven M, Groot MT, Verdonck LF, et al. Cost analysis of HLA-identical sibling and voluntary unrelated allogeneic bone marrow and peripheral blood stem cell transplantation in adults with acute myelocytic leukaemia or acute lymphoblastic leukaemia. Bone Marrow Transplant. 2002;30(4): 243-251. 
21. Blaise D, Fürst S, Crocchiolo R, et al. Haploidentical T cell-replete transplantation with post-transplantation cyclophosphamide for patients in or above the sixth decade of age compared with allogeneic hematopoietic stem cell transplantation from an human leukocyte antigen-matched related or unrelated donor. Biol Blood Marrow Transplant. 2016;22(1):119-124.

22. Di Stasi A, Milton DR, Poon LM, et al. Similar transplantation outcomes for acute myeloid leukemia and myelodysplastic syndrome patients with haploidentical versus 10/10 human leukocyte antigen-matched unrelated and related donors. Biol Blood Marrow Transplant. 2014;20(12):1975-1981.

23. Bashey A, Zhang X, Sizemore CA, et al. T-cell-replete HLA-haploidentical hematopoietic transplantation for hematologic malignancies using post-transplantation cyclophosphamide results in outcomes equivalent to those of contemporaneous HLA-matched related and unrelated donor transplantation. J Clin Oncol. 2013;31(10):1310-1316.

24. Raiola AM, Dominietto A, di Grazia C, et al. Unmanipulated haploidentical transplants compared with other alternative donors and matched sibling grafts. Biol Blood Marrow Transplant. 2014;20(10):1573-1579.

25. Kanate AS, Mussetti A, Kharfan-Dabaja MA, et al. Reduced-intensity transplantation for lymphomas using haploidentical related donors vs HLA-matched unrelated donors. Blood. 2016;127(7):938-947.

26. Baker $\mathrm{M}, \mathrm{Wang} \mathrm{H}$, Rowley SD, et al. Comparative outcomes after haploidentical or unrelated donor bone marrow or blood stem cell transplantation in adult patients with hematological malignancies. Biol Blood Marrow Transplant. 2016;22(11):2047-2055.

27. Burroughs LM, O'Donnell PV, Sandmaier BM, et al. Comparison of outcomes of HLA-matched related, unrelated, or HLA-haploidentical related hematopoietic cell transplantation following nonmyeloablative conditioning for relapsed or refractory Hodgkin lymphoma. Biol Blood Marrow Transplant. 2008;14(11):1279-1287.

28. Solh $\mathrm{M}$, Zhang $\mathrm{X}$, Connor $\mathrm{K}$, et al. Donor type and disease risk predict the success of allogeneic hematopoietic cell transplantation: a single-center analysis of 613 adult hematopoietic cell transplantation recipients using a modified composite endpoint. Biol Blood Marrow Transplant. 2017;23(12): 2192-2198.

29. Gragert L, Eapen M, Williams E, et al. HLA match likelihoods for hematopoietic stem-cell grafts in the U.S. registry. N Eng/ J Med. 2014;371(4):339-348.

30. Bayraktar UD, Champlin RE, Ciurea SO. Progress in haploidentical stem cell transplantation. Biol Blood Marrow Transplant. 2012;18(3):372-380.

31. Pidala J, Kim J, Schell M, et al. Race/ethnicity affects the probability of finding an HLA-A, -B, -C and -DRB1 allele-matched unrelated donor and likelihood of subsequent transplant utilization. Bone Marrow Transplant. 2013;48(3):346-350. 